\title{
Evaluation of Long-term Oncological Outcomes of Inter- Sphincter Resection Compared with Traditional Abdominoperineal Resection in Treatment of Low Rectal Cancers: A Cross Sectional Study
}

\author{
FakhroSadat Anaraki \\ Shahid Beheshti University of Medical Sciences \\ Mahdi Alemrajabi \\ Shahid Beheshti University of Medical Sciences \\ Ramin Shekouhi \\ Shiraz University of Medical Sciences \\ Maryam Sohooli \\ Shiraz University of Medical Sciences \\ Seyed-Ali Sabz ( $\sim$ dr.sabz.md@gmail.com) \\ Shahid Beheshti University of Medical Sciences
}

\section{Research Article}

Keywords: Rectal Cancer, Intersphincteric Resection, Abdominoprineal Resection, Survival, Recurrence of Disease

Posted Date: September 16th, 2021

DOI: https://doi.org/10.21203/rs.3.rs-909458/v1

License: (c) (i) This work is licensed under a Creative Commons Attribution 4.0 International License. Read Full License 


\section{Abstract \\ Objectives}

abdominoperineal resection (APR), is considered the gold standard surgical treatment for low rectal cancer. Patients with low rectal tumors, tumor's distance less than $5 \mathrm{~cm}$ from the anal verge, are likely to require permanent colostomy after APR. Thus, anus-preserving alternative procedures have been tested to avoid the need for permanent colostomy. the aim of the present study is to compare the functional results, and oncological outcome of traditional APR method.

\section{Methods}

Patients' demographic information as well as tumor characteristics were evaluated through a patient's information form. All patients were followed after the operation every three months for two years, and then every six months for at least three years.

\section{Results}

The study was performed on 60 patients with rectal cancer. In the group that performed APR, $9(30 \%)$ patients developed with disease recurrence. In the ISR group, $10(33.3 \%)$ had relapses. Based on this result, the two groups were nearly similar in the recurrence rate of disease and the difference between these two groups was not statistically significant $(P$ value $=0.8)$.

\section{Conclusion}

In summary, the results of the present study concluded that there is no significant difference in efficacy of ISR method compared with the conventional APR in treatment of ultra-low rectal cancer. We surveyed that the ISR method is associated with beneficial long-term survival. Considering the post-operation complication associated with APR surgery including permanent colostomy, and disappointing functional outcomes, we encourage physicians to expand the use of anus-preserving procedures in treatment of low-grade distal rectal cancer.

\section{Objectives}

abdominoperineal resection (APR), is considered the gold standard surgical treatment for low rectal cancer(1). Patients with low rectal tumors, tumor's distance less than $5 \mathrm{~cm}$ from the anal verge, are likely to require permanent colostomy after APR(2). Subsequently, permanent stoma causes sexual activity problems, dietary restriction, and greatly impacts the patient's quality of life(3). Thus, anus-preserving alternative procedures have been tested to avoid the need for permanent colostomy. For low rectal cancers, there are only two procedures available without the need for a permanent stoma; APR with a perineal pseudocontinent colostomy reconstruction, and an intersphincteric resection (ISR)(4).

The inter-sphincteric resection (ISR) was first described by Schiessel et al. and used to maintain sphincter during rectal surgery (5). This external sphincter-saving procedure, has been performed for ultra-low rectal cancer as an alternative option for APR. This method has been associated with desirable outcomes regarding the disease progression, oncology and the incidence of postoperative functional disorders (6). However, ISR could increase the chance of local recurrence, as it may lack the oncological radicality compared to traditional APR(7). The rates of post-operative complications and mortality after ISR surgery have been reported as $0-3.1 \%$ and $7.7-27 \%$ respectively(8). However, to our knowledge there have been very limited studies evaluating the oncologic outcomes of ISR surgery compared with APR.

That said, the aim of the present study is to compare the functional results, and oncological outcome of traditional APR method with the anus-preserving ISR method for treatment of ultra- low rectal cancer.

\section{Methods}


This retrospective cross-sectional study was conducted on 60 patients diagnosed with distal rectal cancer who presented to Taleqani hospital, Tehran, Iran from 2012 to 2019. Patients were divided into two groups. The first group consisted of 30 patients with low rectal cancer who were treated with Inter-sphincter resection (IPR), and the second group including 30 patients with low rectal cancer, who were treated with Abdominoperineal Resection (APR) surgery. In this study, patients' demographic information and characteristics, as well as tumor characteristics were evaluated through the patient's information form. The tumor characteristics included: the distance from the anal, $\mathrm{T}$ and $\mathrm{N}$ stages of the tumors.

Patients who underwent surgery for recurrence or IBD tumors were excluded. All patients were followed after the operation every three months for two years, and then every six months for at least three years. At every outpatient follow up visit, chest and abdominopelvic CT and carcinoembryonic antigen was obtained. The incidence of localized disease (defined as recurrence at pelvic floor, anastomosis site, and the lateral pelvic lymph nodes), total survival and survival without recurrence of patients was evaluated. Ultimately, the oncological outcome in the two groups of were compared. Data were analyzed by SPSS-20 and qualitative variables were analyzed by Chi-square test. For statistical tests, independent t-test with significant level $P$ value $<0.05$ were used.

\section{Ethical consideration:}

All the participants signed an informed consent. The project was approved by the Local Research Ethics Committee (Shahid Beheshti University of Medical Sciences, Iran) with IR.SBMU.MSP.REC.1398.016 code.

\section{Results}

Demographic information. This study was conducted on 60 patients with low rectal cancer. Patients were assigned into two groups of APR and ISR. Findings of the age and gender of patients in the two groups are shown in Table 1. There was no statistically significant difference in terms of age distribution in both groups ( $P$ value $=0.64)$. Thirty-four $(56.6 \%)$ patients were male, and 26 (43.3) were females, which showed no statistical significance in terms of gender distribution.

\section{Table 1. Demographic information and tumor characteristics.}




\begin{tabular}{|c|c|c|c|c|c|}
\hline Variable & & Total & APR; $n=30$ & ISR; n=30 & P-Value* \\
\hline Age & & $57.18 \pm 7.18[41-75]$ & $57.43 \pm 6.81$ & $56.93 \pm 7.64$ & 0.790 \\
\hline \multirow[t]{2}{*}{ Gender } & Male & $34(56.7 \%)$ & $18(60 \%)$ & $16(53.3 \%)$ & \multirow[t]{2}{*}{0.795} \\
\hline & Female & $26(43.3 \%)$ & $12(40)$ & $14(46.7)$ & \\
\hline Tumor distance & & $5.16 \pm 0.38[4.3-6]$ & $5.11 \pm 0.38$ & $5.21 \pm 0.38$ & 0.329 \\
\hline \multirow[t]{3}{*}{ T Stage } & 1 & $20(33.3 \%)$ & $12(40 \%)$ & $8(26.7 \%)$ & \multirow[t]{3}{*}{0.614} \\
\hline & 2 & $24(40 \%)$ & $11(36.7 \%)$ & $13(43.3 \%)$ & \\
\hline & 3 & $16(26.7 \%)$ & $7(23.3 \%)$ & $9(30 \%)$ & \\
\hline \multirow[t]{3}{*}{ N Stage } & 0 & $21(35 \%)$ & $9(30 \%)$ & $12(40 \%)$ & \multirow[t]{3}{*}{0.643} \\
\hline & 1 & $25(41.7 \%)$ & $14(46.7 \%)$ & $11(36.7 \%)$ & \\
\hline & 2 & $14(23.3 \%)$ & $7(23.3 \%)$ & $7(23.3 \%)$ & \\
\hline \multirow[t]{2}{*}{ Neoadjuvant (Chemo)radiation } & Yes & $23(38.3 \%)$ & $10(33.3 \%)$ & $13(43.3 \%)$ & \multirow[t]{2}{*}{0.596} \\
\hline & No & $37(61.7 \%)$ & $20(66.7 \%)$ & $17(56.7 \%)$ & \\
\hline \multirow[t]{2}{*}{ Adjuvant (Chemo)radiation } & Yes & $22(36.7 \%)$ & $9(30 \%)$ & $13(43.3 \%)$ & \multirow[t]{2}{*}{0.422} \\
\hline & No & 38 (63.3\%) & $21(70 \%)$ & $17(56.7 \%)$ & \\
\hline \multirow[t]{2}{*}{ Local recurrence } & Yes & $19(31.7 \%)$ & $9(30 \%)$ & $10(33.3 \%)$ & \multirow[t]{2}{*}{1.000} \\
\hline & No & $41(68.3 \%)$ & $21(70 \%)$ & $20(66.7 \%)$ & \\
\hline Survival (months) & & $40.18 \pm 9.65[16-59]$ & $38.17 \pm 8.35$ & $42.20 \pm 10.56$ & 0.106 \\
\hline
\end{tabular}

Tumor characteristics. The mean tumor distance from the Anal verge in the APR group was $5.11 \pm 0.06 \mathrm{~cm}$ (range $4.5-6 \mathrm{~cm}$ ) and in the ISR group was $5.22 \pm 1.1 \mathrm{~cm}$ (range 4.5-5.8 cm). Comparison between two groups in terms of tumor distance from the anal showed no significant statistical difference $(P$ value $=0.3)$. Tumor characteristics in terms of $T$ and $N$ stage is shown in Table 1 .

Table 2. Factors influencing tumor recurrence 


\begin{tabular}{|c|c|c|c|c|c|c|c|c|c|c|}
\hline \multirow[t]{2}{*}{ Recurrence } & & \multicolumn{3}{|l|}{ Total } & \multicolumn{3}{|l|}{ APR } & \multicolumn{3}{|l|}{ ISR } \\
\hline & & Yes & No & Pvalue & Yes & No & P.value & Yes & No & P.value \\
\hline Tumor Distance & & $\begin{array}{l}5.13 \pm \\
0.31\end{array}$ & $\begin{array}{l}5.18 \pm \\
0.41\end{array}$ & 0.680 & $5.11 \pm 0.40$ & $\begin{array}{l}5.24 \pm \\
0.42\end{array}$ & 0.984 & $\begin{array}{l}5.24 \pm \\
0.42\end{array}$ & $\begin{array}{l}5.15 \pm \\
0.30\end{array}$ & 0.553 \\
\hline \multirow[t]{3}{*}{ T Stage } & 1 & $5(25 \%)$ & $\begin{array}{l}15 \\
(75 \%)\end{array}$ & 0.689 & $3(25 \%)$ & $9(75 \%)$ & 0.880 & $2(25 \%)$ & $6(75 \%)$ & 0.888 \\
\hline & 2 & $\begin{array}{l}9 \\
(37.5 \%)\end{array}$ & $\begin{array}{l}15 \\
(62.5 \%)\end{array}$ & & $4(36.4 \%)$ & $\begin{array}{l}7 \\
(63.6 \%)\end{array}$ & & $\begin{array}{l}5 \\
(38.5 \%)\end{array}$ & $\begin{array}{l}8 \\
(61.5 \%)\end{array}$ & \\
\hline & 3 & $\begin{array}{l}5 \\
(31.3 \%)\end{array}$ & $\begin{array}{l}11 \\
(68.8 \%)\end{array}$ & & $2(28.6 \%)$ & $\begin{array}{l}5 \\
(71.4 \%)\end{array}$ & & $\begin{array}{l}3 \\
(33.3 \%)\end{array}$ & $\begin{array}{l}6 \\
(66.7 \%)\end{array}$ & \\
\hline \multirow[t]{3}{*}{ N Stage } & 0 & $\begin{array}{l}7 \\
(33.3 \%)\end{array}$ & $\begin{array}{l}14 \\
(66.7 \%)\end{array}$ & 1.000 & $3(33.3 \%)$ & $\begin{array}{l}6 \\
(66.7 \%)\end{array}$ & 0.683 & $\begin{array}{l}4 \\
(33.3 \%)\end{array}$ & $\begin{array}{l}8 \\
(66.7 \%)\end{array}$ & 0.886 \\
\hline & 1 & $8(32 \%)$ & $\begin{array}{l}17 \\
(68 \%)\end{array}$ & & $5(35.7 \%)$ & $\begin{array}{l}9 \\
(64.3 \%)\end{array}$ & & $\begin{array}{l}3 \\
(27.3 \%)\end{array}$ & $\begin{array}{l}8 \\
(72.7 \%)\end{array}$ & \\
\hline & 2 & $\begin{array}{l}4 \\
(28.6 \%)\end{array}$ & $\begin{array}{l}10 \\
(71.4 \%)\end{array}$ & & $1(14.3 \%)$ & $\begin{array}{l}6 \\
(85.7 \%)\end{array}$ & & $\begin{array}{l}3 \\
(42.9 \%)\end{array}$ & $\begin{array}{l}4 \\
(57.1 \%)\end{array}$ & \\
\hline \multirow[t]{2}{*}{$\begin{array}{l}\text { Neoadjuvant } \\
\text { (Chemo)radiation }\end{array}$} & Yes & $\begin{array}{l}9 \\
(39.1 \%)\end{array}$ & $\begin{array}{l}14 \\
(60.9 \%)\end{array}$ & 0.397 & $3(30 \%)$ & $7(70 \%)$ & 1.000 & $\begin{array}{l}6 \\
(46.2 \%)\end{array}$ & $\begin{array}{l}7 \\
(53.8 \%)\end{array}$ & 0.255 \\
\hline & No & $\begin{array}{l}10 \\
(27 \%)\end{array}$ & $\begin{array}{l}27 \\
(73 \%)\end{array}$ & & $6(30 \%)$ & $\begin{array}{l}14 \\
(70 \%)\end{array}$ & & $\begin{array}{l}4 \\
(23.5 \%)\end{array}$ & $\begin{array}{l}13 \\
(76.5 \%)\end{array}$ & \\
\hline \multirow[t]{2}{*}{$\begin{array}{l}\text { Adjuvant } \\
\text { (Chemo)radiation }\end{array}$} & Yes & $\begin{array}{l}10 \\
(26.3 \%)\end{array}$ & $\begin{array}{l}28 \\
(73.7 \%)\end{array}$ & 0.264 & $3(33.3 \%)$ & $\begin{array}{l}6 \\
(66.7 \%)\end{array}$ & 1.000 & $\begin{array}{l}6 \\
(46.2 \%)\end{array}$ & $\begin{array}{l}7 \\
(53.8 \%)\end{array}$ & 0.255 \\
\hline & No & $\begin{array}{l}9 \\
(40.9 \%)\end{array}$ & $\begin{array}{l}13 \\
(59.1 \%)\end{array}$ & & $6(28.6 \%)$ & $\begin{array}{l}15 \\
(71.4 \%)\end{array}$ & & $\begin{array}{l}4 \\
(23.5 \%)\end{array}$ & $\begin{array}{l}13 \\
(76.5 \%)\end{array}$ & \\
\hline
\end{tabular}

Frequency of recurrence in patients. In the present study, patients were followed up to 5 years after surgery. In the APR group, 9 (30\%) patients experienced recurrence of the disease. In the ISR group 10 (33.3\%) patients had relapses. Based on this result, the two groups were nearly similar in the recurrence rate of disease and the difference between these two groups was not statistically significant $(P$ value $=0.8)$.

The relationship between age and sex and the stage of the disease with the probability of recurrence of the disease. Concerning the relationship between age and relapse in the studied groups, the results show that the average age of people with recurrence was almost similar to those who did not have recurrence, and the results of independent t-test showed that the relationship between age and the probability of recurrence in any of the surgical methods was not statistically significant $(P$ value $=0.9$ and $P$ value $=0.71)$. Furthermore, gender distribution in people with relapsing disease is almost similar to those who do not have recurrence, and no significant relationship was observed between sex and recurrence amongst both surgical methods $(P$ value $=$ 0.44 and $P$ value $=0.16)$. In terms of tumor stage, patients with $T$ stage $>T 2$ showed higher probability of recurrence. The difference observed was statistically significant $(P$ value $=004$ and $P$ value $=0.02)$.

Survival of patients in the APR method. During the follow up, total of five patients passed away following APR surgery, in which two patients developed with recurrence. Furthermore, out of the five patients, three patients died within the first 3 years of follow up. According to these results, the overall survival rate in the APR method was $83.3 \%$, 3-year survival $90 \%$, and survival of 5 years, $83.3 \%$ (Table 2). 
Survival of patients in the ISR method: In the ISR group, six patients died, which four patients had recurrence. Also, five people died before the third year and one patient died between the third and fifth years. According to this description, the overall survival rate in the ISR method for patients was $80 \%$, 3-year survival rate was $88.3 \%$, and the survival of 5 years was $80 \%$.

\section{Discussion}

The rectal cancer constitutes about $30 \%$ of all colorectal cancers and is considered as one of the most common causes of cancer-related death worldwide(9). Surgical removal of mesorectum and preoperative chemoradiotherapy have greatly improved the survival of patients with rectal cancers. However, these improvements have been less pronounced in patients with distal (ultra-low) tumors compared with tumors in the middle and upper rectum(10). Currently, APR is the standard surgical treatment for distal rectal cancers. That said, disadvantages including modifications in patients' life style due to sphincters removal and permanent ostomy placement are pushing physicians to search for an alternative surgical method. The intersphincteric resection (ISR) method delivers the benefits of preserving the sphincter and the lack of need for ostomy insertion rendering this method as an alternative treatment for these patients. $(11,12)$. However, there have been concerns regarding the safety and efficacy of ISR method in terms of tumor recurrence. The aim of this study was to compare the efficacy of ISR method versus conventional APR, and to compare the long-term oncological outcomes of this anus-preserving surgical method with APR.

In the present study, we reported higher incidence of low rectal cancer amongst men compared to women. This sex-related difference in rectal cancer found in the present study is in line with previous studies(13). That said, the prevalence of colorectal cancer in ascending colon and caecum seems to be significantly higher amongst women compared to men $(12.2 \%$ and $7.3 \%$, respectively), which is associated with more advanced adenomas(13). Furthermore, our study demonstrated that age and gender distribution do not affect the rate of mortality and recurrence amongst low rectal cancer patients. However, previous studies concluded that independent of the tumor location, females showed slightly higher chance of survival compared with men(14).

During this study, total of six patients passed away in the ISR group that compared to the five mortalities in the APR method, showed no significant difference in cancer-related mortality rate. In terms of tumor recurrence, the ISR method revealed no difference in tumor oncologic outcomes compared with APR. The absence of difference in postoperative mortality and recurrence rate between the ISR and APR method, suggest to the fact that ISR method could be a useful alternative treatment option since it is associated with lower rate of post-operation complications. These findings were in accordance with previous studies. A study conducted by Klose et al(15), evaluating the oncologic outcomes of 60 rectal cancer patients that underwent ISR surgery, concluded that ISR method is associated with adequate long-time survival. Furthermore, Yamada et al. observed 107 low-rectal cancer patients that underwent ISR since 1994 till 2006. He concluded that the five-year local recurrence rate following ISR method was 2.5 percent, which considered adequate(16). The five-year survival rate of 80 percent observed in our study is in accordance with previous research(17-20).

Also, in the study of Chamlou et al long-term cancer-associated complications as well as mortality and morbidity rates were studied in patients with rectal cancer managed by ISR surgery. After a mean follow-up of 56.5 months (the range of 13.3 to 68.6 months), either local, distant, or combined relapse occurred in $6(6.6 \%), 8(8.8 \%)$ and 2 (2.2\%) patients respectively. Thirteen patients (14.4\%) died of cancer recurrence in the recent study, and the 5-year and disease-free survival rates were $82 \%(80-97 \%)$ and $75 \%(64-86 \%)$ respectively (21). They concluded that pre-operative chemoradiotherapy was associated with poor functional outcome and fecal incontinence.

During our study, we surveyed that there is uncertainty about the role of neo-adjuvant and adjuvant chemo-radiation in improvement of overall disease recurrence (Table 2). According to the results obtained from the present study, there is no statistically significant difference in local recurrence and mortality rate between patients receiving chemoradiation in both ISR and APR groups. That said, neoadjuvant chemoradiation seems to be an independent predictor factor for fecal incontinence and post-operative functional complications(15). However, it is essential not to undermine the role of chemoradiation in management of rectal cancer, as it previously proven to be associated with lower rate of recurrence and mortality(22). Future 
studies with larger sample population are required to attain other aspects of chemoradiation in treatment of ultra-low rectal cancer.

This study has a number of limitations. Firstly, the present study is a retrospective cross-sectional study and not a prospective trial, which may increase the risk of potential selection and reporting bias. In addition, it can be argued that the present study assesses too few patients, which is mainly due to the disease rarity. Therefore, we encourage physicians to evaluate the longterm oncological outcomes of ISR with larger sample population.

\section{Conclusion}

In summary, the results of the present study concluded that there is no significant difference in efficacy of ISR method compared with the conventional APR in treatment of ultra-low rectal cancer. We surveyed that the ISR method is associated with beneficial long-term survival. Considering the post-operation complication associated with APR surgery including permanent colostomy, and disappointing functional outcomes, we encourage physicians to expand the use of anus-preserving procedures in treatment of low-grade distal rectal cancer.

\section{Declarations}

\section{Disclosure statement:}

\section{Availability of data and materials:}

All data generated or analyzed during this study are included in this published article.

\section{Acknowledgements:}

Not applicable.

\section{Funding:}

No funding was obtained for this study.

Conflict of interest: The authors declare that they have no competing interests.

Informed consent: Written informed consent was obtained from the patients for publication of this article and any accompanying images. A copy of the written consent is available for review by the editor-in-chief of this journal

\section{References}

1. Heald R, Ryall R. Recurrence and survival after total mesorectal excision for rectal cancer. The Lancet. 1986;327(8496):1479-82.

2. Nivatvongs S, Stern HS, Fryd DS. The length of the anal canal. Diseases of the Colon \& Rectum. 1981;24(8):600-1.

3. Anaraki F, Vafaie M, Behboo R, Maghsoodi N, Esmaeilpour S, Safaee A. Quality of life outcomes in patients living with stoma. Indian journal of palliative care. 2012;18(3):176.

4. Nicholls R, Hall C. Treatment of non-disseminated cancer of the lower rectum. Journal of British Surgery. 1996;83(1):15-8.

5. Schiessel R, Karner-Hanusch J, Herbst F, Teleky B, Wunderlich M. Intersphincteric resection for low rectal tumours. British Journal of Surgery. 1994;81(9):1376-8.

6. Jasperson KW, Tuohy TM, Neklason DW, Burt RW. Hereditary and familial colon cancer. Gastroenterology. 2010;138(6):2044-58.

7. Bretagnol F, Rullier E, Laurent C, Zerbib F, Gontier R, Saric J. Comparison of functional results and quality of life between intersphincteric resection and conventional coloanal anastomosis for low rectal cancer. Diseases of the Colon \& Rectum. 
2004;47(6):832-8.

8. Braun J, Treutner KH, Winkeltau G, Heidenreich U, Lerch MM, Schumpelick V. Results of intersphincteric resection of the rectum with direct coloanal anastomosis for rectal carcinoma. The American journal of surgery. 1992;163(4):407-12.

9. Haggar FA, Boushey RP. Colorectal cancer epidemiology: incidence, mortality, survival, and risk factors. Clinics in colon and rectal surgery. 2009;22(4):191.

10. Vernava 3rd A, Moran M, Rothenberger D, Wong W. A prospective evaluation of distal margins in carcinoma of the rectum. Surgery, gynecology \& obstetrics. 1992;175(4):333-6.

11. Komori K, Kimura K, Kinoshita T, Ito S, Abe T, Senda Y, et al. Necessary circumferential resection margins to prevent rectal cancer relapse after abdomino-peranal (intersphincteric) resection. Langenbeck's archives of surgery. 2016;401(2):189-94.

12. Tsukamoto S, Kanemitsu Y, Shida D, Ochiai H, Mazaki J. Comparison of the clinical results of abdominoperanal intersphincteric resection and abdominoperineal resection for lower rectal cancer. International journal of colorectal disease. 2017;32(5):683-9.

13. White A, Ironmonger L, Steele RJ, Ormiston-Smith N, Crawford C, Seims A. A review of sex-related differences in colorectal cancer incidence, screening uptake, routes to diagnosis, cancer stage and survival in the UK. BMC cancer. 2018;18(1):1-11.

14. Schmuck R, Gerken M, Teegen E-M, Krebs I, Klinkhammer-Schalke M, Aigner F, et al. Gender comparison of clinical, histopathological, therapeutic and outcome factors in 185,967 colon cancer patients. Langenbeck's archives of surgery. 2020;405(1):71-80.

15. Klose J, Tarantino I, Kulu Y, Bruckner T, Trefz S, Schmidt T, et al. Sphincter-preserving surgery for low rectal cancer: do we overshoot the mark? Journal of Gastrointestinal Surgery. 2017;21(5):885-91.

16. Yamada K, Ogata S, Saiki Y, Fukunaga M, Tsuji Y, Takano M. Long-term results of intersphincteric resection for low rectal cancer. Diseases of the Colon \& Rectum. 2009;52(6):1065-71.

17. Bonjer HJ, Deijen CL, Abis GA, Cuesta MA, Van Der Pas MH, De Lange-De Klerk ES, et al. A randomized trial of laparoscopic versus open surgery for rectal cancer. New England Journal of Medicine. 2015;372(14):1324-32.

18. Akasu T, Takawa M, Yamamoto S, Ishiguro S, Yamaguchi T, Fujita S, et al. Intersphincteric resection for very low rectal adenocarcinoma: univariate and multivariate analyses of risk factors for recurrence. Annals of Surgical Oncology. 2008;15(10):2668-76.

19. Weiser MR, Quah H-M, Shia J, Guillem JG, Paty PB, Temple LK, et al. Sphincter preservation in low rectal cancer is facilitated by preoperative chemoradiation and intersphincteric dissection. Annals of surgery. 2009;249(2):236-42.

20. Hohenberger W, Merkel S, Matzel K, Bittorf B, Papadopoulos T, Göhl J. The influence of abdomino-peranal (intersphincteric) resection of lower third rectal carcinoma on the rates of sphincter preservation and locoregional recurrence. Colorectal Disease. 2006;8(1):23-33.

21. Chamlou R, Parc Y, Simon T, Bennis M, Dehni N, Parc R, et al. Long-term results of intersphincteric resection for low rectal cancer. Annals of surgery. 2007;246(6):916-21; discussion 21-2.

22. Group CCC. Adjuvant radiotherapy for rectal cancer: a systematic overview of 8507 patients from 22 randomised trials. The Lancet. 2001;358(9290):1291-304. 